\title{
IMAGINÁRIO SOCIAL, NORMA CULTA E ENSINO DENTRO E FORA DA SALA DE AULA*
}

Beth Brait ${ }^{* *}$

Quem não vê bem uma palavra não pode ver bem uma alma

Fernando Pessoa

Imagem: semelhança ou vestígio das coisas, que se pode conservar independentemente das próprias coisas

Abbagnano

A idéia de refletir, mais uma vez, sobre a questão do ensino da língua portuguesa dentro e, principalmente, fora da sala de aula implica, necessariamente, o difícil enfrentamento de duas vias em constante cruzamento e que não podem ser ignoradas ou subestimadas. De um lado, nos confrontamos com a necessidade de explicitar uma concepção de língua e de linguagem, o que necessariamente cabe ao universo acadêmico, ao conjunto das diferentes correntes dos estudos lingüísticos, única instância capaz de estabelecer uma política lingüística, como propõe nesse momento a ABRALIN, e que deve orientar a produção e a divulgação desse conhecimento. O que não é fácil uma vez que, felizmente, constituímos um universo heterogêneo. Por outro lado, é necessário enfrentar, também, uma outra realidade que está além do universo

- O tema desta conferência está dentro das pesquisas desenvolvidas com o auxílio do CNPq, processo 300098/93-6.

* PUC-SP e USP. 
BRAIT, Beth. Imaginário social, norma culta e ensino dentro e fora da sala de aula.

acadêmico, mas que o atravessa com uma força enorme, na medida em que constitui o imaginário dominante sobre a língua e que é divulgado, alimentado e consumido fora das salas de aula, contando com a força da mídia.

Deve ficar claro desde já que essa preocupação não é original, não é pessoal, embora minha trajetória como professora, autora de livros didáticos e paradidáticos, como pesquisadora que encara a linguagem como um processo dialógico e interacional e que se dedica tanto à literatura quanto à linguagem oral possa, de fato, confirmar esse interesse como um dos eixos centrais do meu percurso. O que é partilhado, o que é comum e necessário reconhecer é o fato dessa questão ser a maior para todos os que estão voltados para os estudos e o ensino da língua. Ela se faz presente no nosso dia-adia profissional, assumindo formas as mais diferenciadas. E é justamente a observação de vários aspectos com os quais convivemos diariamente, quer na condição de teóricos da linguagem, quer de usuários da língua, quer de professores ou mesmo, e especialmente, de consumidores da mídia, que escolhi o caminho que exponho a seguir.

Desempenhando diariamente todos esses papéis, ao mesmo tempo ou de forma alternada, é que podemos perceber o quanto, dentro da complexidade do conceito de língua, e especialmente de linguagem, há algumas dimensões institucionalizadas que, atravessando cada uma dessas posições, atuam como se fossem constitutivas de uma língua verdadeira, determinando comportamentos, atitudes, posturas explicitadas, e transformado-se em objetos de consumo amplamente aceitos. Para dar forma a essa discussão, terei necessariamente de retomar alguns conceitos e as maneiras como esses conceitos são mobilizados social e culturalmente, assumindo mais uma vez, com Guimarães Rosa e Bakhtin, que a vida e a linguagem são a mesma coisa, com Fernando Pessoa, que "quem não vê uma palavra não vê uma alma" e, com a filosofia, que podemos definir a "imagem como semelhança ou vestígio das coisas, que se pode conservar independentemente das próprias coisas".

Começo retomando a idéia de que falar bem e escrever bem, mais que uma necessidade de todo cidadão que precisa ingressar no mercado de trabalho e manter-se nele, argumento que hoje em dia estabelece a ligação entre aprendizado de língua e possibilidade de emprego, é um forte desejo construído pelo imaginário social e cultural e ao qual os indivíduos se submetem com maior ou menor grau de consciência. Se na sala de aula a idéia de aprender falar e escrever bem está ainda ligada, em larga medida, ao sacrifício, sem que se tenha encontrado a melhor maneira de estabelecer a ligação entre necessidade e desejo, a mídia, por sua vez, vem explorando com muita propriedade, ao menos no sentido mercadológico que o termo "propriedade" pode 
assumir, a articulação desejo/necessidade construída social e culturalmente e evidentemente difundida e alimentada por essa mídia.

Com a mesma força da ideologia editorial da auto-ajuda, a mídia impressa, e mais recentemente a televisiva, encontra fórmulas para forjar um ensino do que se considera a verdadeira língua portuguesa, explorando com toda naturalidade o imaginário dominante. Historicamente afinada, já que vivemos um momento em que o indivíduo deve crer que é o único responsável por seus fracassos e seus sucessos, essa concepção de língua e de seu ensino reparte os indivíduos em duas categorias: os que têm o dom de conhecer a verdade, os que se caracterizam como iniciados e que, aparentemente, podem passar essa verdade por meio de receitas, de poções mágicas, e os outros, os aprendizes de feiticeiros, os que não possuem o conhecimento, o poder de se auto-bastar, mas que deverão receber dos iniciados as fórmulas rápidas e infalíveis para atingir a perfeição. Como se ensino e aprendizagem mantivéssem uma relação imediata de causa e efeito. É disso que se trata. Estamos lidando com crenças, com crendices, com poderes que se propõem a forjar a realidade, independentemente de sua existência. Esse imaginário está presente também, por exemplo, na enorme quantidade de artigos assinados por meio dos quais o jornal atribui-se a função de órgão empenhado na preservação de uma língua portuguesa verdadeira e única.

Assim, é a partir desse conjunto de fórmulas para conscientizar e ensinar que se pode apreender um conceito de língua bastante restritivo em que gramática, norma padrão, norma culta, falar e escrever bem aparecem como sinônimos perfeitos, de forma a articular desejos e necessidades de um público amplo e heterogêneo. Mesmo que o resultado dessa articulação seja tão ilusório, diáfano e perecível quanto o das toneladas de obras sobre a auto-ajuda em outros campos.

Assim sendo, embora a definição de falar bem não implique necessariamente falar correto, no sentido da variante padrão, é por esse imaginário social muito forte, voltado para o que vem a ser a norma padrão, escrita e/ou falada, e para as implicações pessoais, culturais e sociais que decorrem de sua utilização, que se estabelece a implicação falar bem/falar correto. Apagando o fato de que a língua se realiza nas interações $\mathrm{e}$, por isso mesmo se apresenta como um conjunto de possibilidades que se formalizam historicamente, socialmente, culturalmente, o falar e escrever correto se identificam, por essa via, única e exclusivamente com o domínio da gramática num de seus sentidos, ou seja, de "conjunto de regras que devem ser seguidas". Esse domínio, cujas implicações sociais traduzem-se pelas sanções - não fala bem e por isso não pode ser eleito, por exemplo -, está necessariamente ligado a um aprendizado, a uma 
BRAIT, Beth. Imaginário social, norma culta e ensino dentro e fora da sala de aula.

dimensão institucional, e para ser ensinado, mas não necessariamente apreendido, precisa socorrer-se de instrumentos institucionalizados como é o caso dos dicionários e das gramáticas normativas.

E é aí que a mídia entra, a meu ver, com a proposta de preencher as lacunas deixadas pela escola. Tomemos como primeiro exemplo o caso dos manuais de estilo propostos pela mídia e que, em princípio, deveriam servir somente aos profissionais ligados ao veículo que elaborou as normas que, necessariamente, respondem à maneira como o jornalismo é concebido e deve, portanto, ser praticado. O pressuposto é que o profissional da área já tenha um domínio da língua portuguesa e vá, pelo manual, adaptar esse domínio às especificidades do discurso jornalístico e do estilo do jornal em questão.

O Manual geral da redação, publicado pelo jornal Folha de S. Paulo (1987, 2. ed. rev.), traz como epígrafe, na segunda capa, uma frase do fundador do jornal, Olival Costa, que deixa bem claro o que se entenderá por discurso jornalístico, justificando a existência do manual e o fato de ele ser porta-voz da redação que, por sua vez, se identifica com esse jornal: "Quem quer literatura busca-a nos livros. A função do jornal é informar. Mas informar não é apenas noticiar: é, a um tempo, selecionar e orientar. No esforço de selecionar se acha subentendida a obrigação de criticar". Para orientar a produção, a realização desse conceito de jornal, o manual organiza-se em forma de verbetes, tal qual um dicionário, uma enciclopédia. Esses verbetes estão organizados em nove partes, incluindo uma curta Apresentação, em que há a explicação de como usar o manual, e um Índice remissivo.

Desse conjunto, há seis itens, intitulados Política editorial, Estrutura da Folha, Padronização de estilo, Procedimentos profissionais, Convenções gráficas e Vocabulário jornalístico, incluindo o subitem anexos, que cumprem perfeitamente a expectativa criada pelo título, ou seja, de que o objetivo da obra é ser "um manual geral da redação", um utilitário criado para auxiliar os profissionais da área que trabalham nesse jornal específico que é a Folha de S. Paulo. Entretanto, e é isso que diz respeito ao que estamos tratando aqui, há um item denominado Normas gramaticais, o que nega a idéia de que o manual seja inteiramente específico. Na verdade, provavelmente por força da longa experiência, o jornal inclui em seu manual um conjunto de verbetes sobre gramática, pressupondo que o profissional não tem o domínio da língua ou, ao menos, do padrão exigido pelo jornal. E o que caracteriza esse conjunto de verbetes? O que o jornal pressupõe que seu profissional não domine? Como vai viabilizar esse conhecimento? Naturalmente, pelos mesmos caminhos trilhados insatisfatoriamente pela escola. 
Os verbetes reúnem várias questões ligadas ao léxico, à sintaxe, à acentuação, à pontuação, tratadas sem qualquer relação umas com as outras. Assim, merecem verbetes o caso de expressões de uso corrente, mas que são consideradas erro, como acontece com "a nível de", "ao par", ou a necessidade de distinguir significados como em "ao invés" e "em vez de". O que se observa, surpreendentemente, é a transcrição pura e simples do que dizem as gramáticas ou os dicionários, fontes exclusivas do ensino a que se submeteram os profissionais considerados "deficientes lingüísticos" e que têm, nessa muleta representada pelo conjunto de verbetes desse item, mais uma suposta oportunidade de correção, de aprendizado do que já deveriam saber.

O problema da acentuação bem como o da pontuação, por exemplo, é apresentado em forma de reconstituição pura e simples, só que reduzida e sem mencionar as fontes, das regras atuais de acentuação e das normas de utilização dos sinais de pontuação, exatamente como são apresentadas em qualquer gramática ou manual escolar padrão. O eterno tema da sintaxe de colocação, envolvendo os pronomes, vai merecer o verbete "colocação pronominal", de poucas linhas, que remete a um outro sobre o "Se" que, por sua vez, remete a "Vendem-se casas" que, também, por sua vez, remete ao verbete "Se", anteriormente mencionado. Nem os exemplos são atualizados. Lá estão os mesmos, sistematicamente repetidos pelos manuais e gramáticas. Há, ainda, a regência de verbos como aspirar, assistir, esquecer, informar, interessar, visar, que em momento algum os autores pensam em olhar para a realidade, examinar o universo com a luneta, insistindo, mutatis mutandi, que o sol gira em torno da terra porque assim diziam os antigos.

A inutilidade desses verbetes pode ser constatada diariamente nos textos que aparecem no jornal Folha de S. Paulo, como em qualquer outro jornal que se arvore a acreditar que o manual, e esses poucos verbetes baseados na imposição dessa gramática entendida como "conjunto de regras que devem ser seguidas", pode resolver, pelos mesmos ínvios caminhos percorridos pela escola, o problema do domínio da língua.

É possível radicalizar a exemplificação, tomando uma ocorrência apenas folclórica, mas exemplar no sentido de ironizar a tentativa de dominar os erros no dia-adia do jornal. Na Folha de 20 jun. 1998, na seção Erramos, aparece a seguinte "errata": "Após o fechamento da edição do Guia da Folha SP de ontem, foi alterada as programação de alguns cinemas...".

Se pegássemos um outro manual, como é o caso do Manual de redação e estilo do jornal $O$ Estado de S. Paulo, verificaríamos o mesmo imaginário, as mesmas pre- 
tensões, as mesmas incoerências e contradições verificadas entre "as normas que devem ser seguidas" e a presença diária nas páginas dos jornais dos problemas apontados nas instruções para o domínio da língua. Claro que esses jornais têm diferenças, ou não seriam dois. Uma dessas diferenças, e é a que aqui nos interessa, está na explicitação do conceito de língua, que aparece logo após uma espécie de resposta a outros manuais do gênero:

\begin{abstract}
"Este Manual, convém ressaltar desde logo, não tem semelhança alguma com outros textos adotados em outras paragens, aparentemente forjados para a fabricação e série de jornalistas de proveta, robôs infensos a qualquer gênero de emoção. Embora originalmente concebido para afastar as muitas pedras no caminho dos profissionais da imprensa, ou preveni-los de sua existência, ultrapassou as fronteiras fixadas para uma espécie de código de defesa do idioma e ganhou um universo mais amplo (...)"

"Habituado a conciliar harmoniosamente a tradição e a modernidade, síntese que ajuda a explicar o vigor exigido aos 115 anos de existência, o Estado tem consciência de que um idioma vivo, como o Português, está sujeito a mudanças influenciadas pelos novos tempos - é compreensível que tais mudanças ocorram com velocidade maior na linguagem jornalística. Mas o Estado recusa a tese segundo a qual o empobrecimento da língua é uma imposição da vida contemporânea e rejeita a falácia que considera prerrogativa de pedantes o uso de repertórios vocabulares menos miseráveis. Não poderia ser outra a posição de um jornal que sempre conduziu, entre tantas outras bandeiras, a da preservação a qualquer preço da cultura nacional. E que, entre tantos outros feitos, se confunde com as origens da Universidade de São Paulo".

"O trabalho iniciado há três anos e agora reunido nas páginas seguintes não abriga a pretensão de transmitir por osmose o domínio do Português. Nenhum Manual, sejam quais forem as suas dimensões, pode neutralizar por si só, e simultaneamente, a erosão ocorrida no ensino básico, a decadência dos cursos secundários e a deterioração da Universidade. Da mesma forma, só escreve com competência quem lê regularmente. Manuais como o do Estado não equivalem a uma espécie de mapa da mina; são instrumentos de apoio, mas essenciais neste quadro de aguda crise do idioma" (p. 9).
\end{abstract}

Mas não são unicamente os manuais e os jornais citados que apontam para "a aguda crise do idioma", para os culpados dessa "decadência", considerando os "casos escabrosos"; e aqui estou recuperando o léxico presente nos revoltados artigos. A 
própria imprensa se encarrega de abrir inúmeros espaços para discutir a língua portuguesa e seu usos inadequados. Se não é o caso de fazer aqui uma estatística dos artigos publicados em revistas e jornais brasileiros, nos últimos cinco anos, sobre o assunto, basta retomar um que parece feito a propósito para o que estou tentando discutir aqui. A revista Bravo!, que é uma excelente revista de cultura, uma das que constituem o recente mercado de revistas culturais, como é o caso das revistas Cult e República, na seção "Sempre Alerta", do n. 2, ano 1, nov. 1997, publicou um artigo do jornalista Sérgio Augusto, intitulado "Regando a flor", com o subtítulo "A imprensa cultiva erros crassos de língua e clichês". Chamo atenção não só para o título, e seu intertexto literário, mas principalmente para o subtítulo, que é bastante expressivo enquanto forma de evidenciar o curto alcance dos manuais de redação e estilo. O texto, para confirmar a idéia contida no subtítulo, apresenta vários exemplos que, se tirados de redação de alunos das escolas públicas, seriam fortes bandeiras para desqualificar os alunos, os professores e o ensino público, como a imprensa se incumbe de fazer constantemente. O primeiro exemplo é a frase "já dá pra mim andar", ditas por Emerson Fittipaldi, por ocasião de seu acidente, e transmitidas pelo Jornal Nacional. Ela motiva não apenas a censura do articulista ao contraventor, imputando ao veículo o crime hediondo da retransmissão em cores e ao vivo, mas oferece, curiosamente, a solução: esse mesmo veículo pode oferecer o aprendizado por meio de um comercial, portanto por meio de um instrumento que é de sua natureza. Reconhecendo que o famoso corredor de automóveis conseguiu comunicar-se tranqüilizando os fãs, observa, com outras palavras, que enquanto enunciador ele está inteiramente desqualificado e deveria começar a prestar a atenção ao tal comercial:

\footnotetext{
"Seus fãs podem ter ficados tranqüilos, mas quem dá mais importância ao uso correto da língua do que a corridas de carro e à navegação aérea ficou acima de tudo chocado com a declaração do automobilista. Ao atropelar a gramática de maneira tão acintosa, Fittipaldi demonstrou, entre outras coisas, não ser um telespectador atento ao que de melhor os nossos canais abertos costumam oferecer: os intervalos comerciais nos últimos meses valorizados por uma campanha promocional do McDonald's cujo destaque era um simpático professor de português que se esmerava em corrigir as mais corriqueiras derrapadas lingüisticas de nossa ignara juventude. Em sua primeira aula, o professor ensina que pronomes oblíquos não podem ser usados antes do verbo, que não se deve dizer 'Isto (no caso, um hamburguer) é pra mim comer', e sim 'Isto é para eu comer'. Espera-se que a moçada tenha aprendido essa lição, até hoje ignorada por Fittipaldi" (Bravo!, nov. 1997, ano 1, n. 2, p. 16).
} 
Depois de várias considerações, o autor do artigo sugere que outras campanhas dessa natureza sejam promovidas também pelas multinacionais a fim de que as pessoas possam, por exemplo, "aprender a pronunciar direito algumas palavras e expressões inglesas onipresentes em nossas conversas, right?", missão que poderia ser protagonizada pela Coca-Cola, de forma que os telespectadores aprendessem que não se diz "cederrum", mas "cederrom". Para a Pepsi, por exemplo, sugere uma outra missão:

\begin{abstract}
"reaproximar a imprensa da última Flor do Lácio, sistematicamente vilipendiada por toda sorte de visigodos. Não faço a menor idéia de como ela poderia ser arquitetada para eficazmente compensar os estragos causados pelos cabeças-de-bagre, que em nossas redações matam o idioma na canela e baixam o sarrafo no estilo. Sei apenas que dela precisamos com máxima urgência, quando nada porque a quase totalidade dos nossos parcos alfabetizados só se relaciona com a palavra escrita por meio de jornais e revistas. E também porque o empenho de alguns veículos de informação em aprimorar a qualidade de seus textos não se tem mostrado dos mais eficientes. Ainda continuamos sendo agredidos por erros crassos de ortografia, concordância e regência, para não falar dos clichês e outros vícios de linguagem de que nem os craques do jornalismo conseguem escapar" (Bravo!, nov. de 1997, ano 1, n. 2, p. 16).
\end{abstract}

Depois de propor que alguns vocábulos usados indiferenciadamente, e por puro modismo, sejam eliminados, com seria o caso de cult, colocar (no sentido de expor uma idéia), resgatar (como sinônimo de recuperar, restaurar) e detonar (como metáfora de lançamento), dos famigerados a nivel de, otimizar, agilizar, sinalizar, praticidade ou posicionamento, e de alguns clichês, como é o caso de lugar ao sol, ao apagar das luzes, tiro de misericórdia (...) página virada, das tripas coração etc., o autor faz referência às providências que alguns jornais tomaram em relação a esses descalabros, antecipando alguns resultados:

"alguns jornais andaram providenciando a contratação de professores
de língua portuguesa para dar aulas aos seus funcionários e aos seus
leitores. Mês passado foi a vez do Jornal do Brasil, logo seguido por
O Globo, que, espertamente, apelou para a sapiência de Pasquale Cipro
Neto, o tal professor celebrizado pelos comerciais do McDonald's. Se
os dois mestres terão êxito, dentro e fora da redação, só o tempo dirá.
Na Folha de S. Paulo, pioneira nessa ação iluminista, os resultados
ficaram bem aquém das expectativas. Em suas páginas, ainda circu- 
lam, impunemente, várias das barbaridades relacionadas no parágrafo anterior, além de outras que devem provocar urticárias simbólicas no jornalista Cláudio Júlio Tognolli, patrulheiro graduado dos chavões da imprensa brasileira" (Bravo!, nov. 1997, ano 1, n. 2, p. 17).

O que se pretende aqui não é analisar passo a passo a forma como o imaginário sobre norma culta, a norma padrão, considerada a verdadeira língua está disseminado nesse artigo, mas chamar atenção para as formas do que estou chamando, resumindo a proposta dos manuais, de "saneamento lingüístico básico do jornalismo". Esse saneamento está sugerido pelo autor com instrumentos que, mesmo para os casos apontados por ele, são inteiramente inócuos. Ao tratar o domínio da língua apenas no sentido de gramática enquanto "conjunto de regras a serem seguidas", tanto a escola, quanto os manuais, quanto o professor que conhece todas as regras, terão exatamente o mesmo resultado. Esse resultado o autor do artigo constata quando diz que "na Folha de $S$. Paulo, pioneira nessa ação iluminista, os resultados ficaram bem aquém das expectativas".

O que ele ainda estaria por ver é que, nesse mesmo jornal, alguns meses depois desse seu comentário, a quarta capa de um encarte do Time traria uma propaganda do CD-ROM Nossa Língua Portuguesa e, juntamente com a foto do produto, que inclui uma fotografia do autor (e aqui destaco novamente as formas de centralizar o domínio do conhecimento num indivíduo, numa figura que se torna uma imagem), havia um texto cujo título era: "Você contrataria este homem como professor de português de seu filho?". Na seqüência, um texto bastante coloquial, elaborado de acordo com o público-alvo, e por isso incluindo termos e expressões como dá dicas, esclarecer diversas dúvidas que o idioma apresenta, acessados, navegue nesse programa, atualizações lingüísticas, nós poderíamos dizer, nem sempre aceitas pelos guardiães da língua "pura e verdadeira". Mas trazia, também, e por pura ironia do destino, um quizer com " $z$ ", que nenhuma modernidade pode justificar num anúncio de ensino de língua no sentido de gramática como normas a serem seguidas. Isso significa que os autores não só não conhecem as normas de ortografia, presentes nas gramáticas, nos manuais escolares e nos manuais de redação jornalística, como não utilizaram o corretor ortográfico do computador que, nesse caso, resolveria sozinho o problema. O tal professor, algum tempo depois, assinalou o acontecido em sua coluna da mesma $\mathrm{Fo}_{\mathrm{O}}$ lha de S. Paulo, expressando da maneira transcrita a seguir que, por si só, já daria uma belíssima análise discursiva, uma vez que o professor, imagem do guru que domina a língua portuguesa conforme o imaginário dominante, vinha justamente criticando 
uma série de textos publicitários que cometiam essas "barbaridades" que tornam a língua cada vez mais inculta e menos bela:

“Até o CD-ROM Nossa Língua Portuguesa, do professor Pasquale,
que por acaso sou eu, caiu na arapuca. Recentemente foi publicada
uma propaganda em que se lia 'quizer' com ' $\mathrm{z}$ '. Não me restou nada
além de lamentar a presença constante do capeta, que está sempre de
plantão.

Espero que a agência já tenha feito o que fez a do edifício e o que deveriam fazer a da loja de eletrodomésticos e a do banco oficial, ou seja, espero que na próxima apareça 'quiser' com 's', como determinam as normas ortográficas em vigor" (Folha de S. Paulo, 11 jun. 1998, p. 3-2).

Deve ficar claro, a partir desses comentários, que essas observações não têm nada a ver com a idéia de que a gramática e a língua padrão não devam ser ensinadas na escola, ou praticadas enquanto variante padrão, como no caso jornalístico aqui mencionado. Isso seria um absurdo, uma falácia, e estaríamos concordando com a idéia reacionária de que a escola só deve ensinar o que as pessoas já sabem, excluindoas do acesso a outras instâncias de conhecimento. A concepção de língua como sistema de normas a serem seguidas é tão contraproducente quanto a sua substituição pelo ensino da consciência das normas do oral. Nos dois casos, o problema que se coloca é o do conhecimento e da descrição da língua e da linguagem, função do lingüista em sentido amplo, e o do repasse desses conhecimentos, dessas fatias de conhecimento, como se esse domínio consciente funcionasse como domínio da língua.

As observações feitas até aqui, e que tomam o atalho do ensino da língua fora da escola, mas a partir de um imaginário dominante, têm a ver com um enfrentamento menos parcial, limitado, do conceito de língua que, naturalmente, é mais amplo, porque inclui ou possibilita, o conceito de gramática ou dos vários sentidos que o termo gramática pode assumir, contemplando a idéia da variação, da função específica na constituição dos sujeitos, da amplitude dos gêneros mobilizados na diversidade das atividades humanas e até mesmo, mas não exclusivamente, da consciência dos mecanismos lingüísticos. Muitos desses aspectos, ou seja, os que contemplam um conceito de língua e de linguagem diferenciado de "conjunto de regras que devem ser seguidas" e que muito tem a ver com a idéia de ensino e de aprendizado, já foram tratados com muita clareza e lucidez por vários teóricos brasileiros, incluindo para destaque os lingüistas Sírio Possenti e Wanderley Geraldi. 
É evidente que essa história não termina aqui e que poderia ser recomeçada se acompanhássemos outros fios dessa espécie de teia de aranha, labirinto de muitos meandros, que estabelece as maneiras de enfrentar a língua, seu aprendizado, seu ensino e sua participação na vida humana. Se o ensino da língua fora da sala de aula assume ares de "saneamento lingüístico básico", como já disse, tomando o lugar da escola enquanto método e imaginário e, por isso, falando do mesmo modo e do mesmo lugar, poderíamos chamar para uma conversa rápida outro grupo, o dos falantes/ escritores que, muitas vezes, além de assumir e praticar a língua como "conjunto de possibilidades", expande seu espaço para o domínio do teórico, construindo uma metalinguagem situada entre o literário e o não-literário, mostrando mais uma vez que quando se fala em língua não se está falando necessariamente da mesma coisa. E entres eles também há muitas divergências; inteiramente saudáveis para a exposição do aluno, do falante, à complexidade representada pela língua e pela linguagem e pelo imaginário que as envolve.

Esse é o caso, dentre outros, de Molière, Fernando Pessoa, Clarice Lispector e João Guimarães Rosa, quatro criadores que, em meio às criações lingüístico-literárias, não deixaram de expor as diferenças existentes entre os vários falares, entre falar e escrever e, necessariamente, fizeram aproximações e promoveram namoros existentes entre as múltiplas dimensões da língua. Esses escritores foram escolhidos não como exemplo de língua criativa e bem manejada, como se poderia imaginar de imediato e que seria absolutamente lícito, mas por terem transformado essa questão em tema de alguns de seus escritos, propiciando o conhecimento de suas concepções.

Assim, o ponto de partida dessa conversa pode ser O burguês fidalgo, de Molière, que numa recente versão feita para o teatro brasileiro ganhou o nome de Burguês ridículo. O que se observa no texto original, e que na peça ganha uma grande amplitude, é que o autor explora de maneira muito especial o imaginário existente em torno do que seria o bem falar, assim como os diferentes falares representados por diferentes classes. É possível observar que o conceito de falar bem, enquanto sinônimo de falar correto, está ligado a um imaginário social, cultural, que coloca a dimensão desse "bem falar" em pelo menos duas perspectivas. De um lado, como o falar próprio dos bem nascidos, dos que têm acesso a bens materiais e intelectuais e que, por isso mesmo, destacam-se socialmente. Ou daqueles que, por diversos caminhos, ascendem na escala social. Assim, da perspectiva de um imaginário sociolingüístico, ascender do ponto de vista socioeconômico implicaria, necessariamente, a aquisição de um "estágio lingüístico superior". 
BRAIT, Beth. Imaginário social, norma culta e ensino dentro e fora da sala de aula.

É assim que a personagem M. Jourdain vai personificar esse imaginário, propiciando o desvendamento de um outro lado, ou seja, o da figura do falante dessa norma idealizada, desse "estágio lingüístico superior" e, especialmente, do que se imagina venha a ser essa norma. É nesse sentido que M. Jourdain aparece como um foco de observação crítica e como um alvo de ridicularização, o que interfere no conceito de língua "superior".

Se o objetivo da personagem burguês fidalgo/burguês ridículo de Molière é falar como fala a aristocracia, ou como ele imagina que fala essa aristocracia, tornando-se, por esse ângulo, um instrumento/alvo da crítica do escritor francês, não é menos verdade que as críticas ao nosso atual Presidente da República vêm esmaecidas, em muitos momentos, pelo fato de ele ser bem dotado intelectualmente, delimitando-se esse dote ao fato de que ele não apenas fala bem o Português, mas também domina outras línguas. $\mathrm{O}$ acesso a línguas, no sentido do domínio de mais de um idioma, a posse do que se considera a "língua ideal, correta, e portanto verdadeira", são aspectos que sem dúvida configuram um pólo bastante forte do imaginário sociocultural, transitando da impiedosa pena de Molière ao orgulho pouco dissimulado dos brasileiros em relação aos dotes lingüísticos do atual chefe da nação.

Para colaborar na composição desse panorama diversificado em que um imaginário em torno da norma culta se faz presente dentro e fora da sala de aula, é possível recuperar o grande poeta da língua portuguesa, Fernando Pessoa, que aqui será surpreendido, não em seus poemas e nas diversas posturas dos heterônimos, mas numa recente coletânea, de até então inéditos em prosa, intitulada $A$ língua portuguesa, e cuja edição, feita por Luísa Medeiros, vai colaborar na composição de um panorama a respeito das diferenças que cercam as humanas atividades do falar e do escrever. $\mathrm{O}$ grande poeta português, num emaranhado teórico que traz as marcas de um descomprometido caderno de apontamentos, vai entender "a palavra falada como um fenômeno natural; a palavra escrita como um fenômeno cultural”. (...) Assim sendo, e como ele afirma, "pertencendo, pois, a mundos (mentais) essencialmente diferentes, os dois tipos de palavras obedecem forçosamente a leis ou regras essencialmente diferentes". Certamente a diferença entre "natural" e "cultural" estabelecida pelo poeta segue uma direção que não obedece, por assim dizer, um conceito científico de língua. Mas, nesse conjunto de escritos, Fernando Pessoa, ele mesmo, vai dividir sua reflexão em duas partes intituladas "O problema da ortografia" e "Defesa e ilustração da língua portuguesa". Vale a pena seguir seus passos e encontrar seus apontamentos sobre língua, normas e falas e observar a força da idéia de cultura e conhecimento para estabelecer as diferenças existentes entre língua e fala. Se a forma de encarar as dife- 
renças entre oral e escrito parece estranha, mesmo não esquecendo seu próprio ensinamento de que "O poeta é um fingidor"... e que ele jamais retocou para publicação, basta observar as seguintes afirmações para entender como falar de língua significa falar de coisas muito diferentes que não têm homogeneidade, nem enquanto objeto nem enquanto ponto de vista.

\footnotetext{
"Chegamos finalmente ao caso da verdadeira palavra escrita, o de como ela se fixa - a palavra escrita da literatura e da cultura, dos literatos e outros letrados (...)” (p. 22).
}

"Ora sendo a palavra escrita um produto de cultura, nisto, como em tudo mais, o indivíduo tem o direito de adoptar o que quiser - a que Ihe parecer melhor ou mais conveniente. Quer isto dizer que - ao contrário do que quer Dr. Agostinho de Campos - a cada um tem direito a escrever na ortografia que quiser; que, tecnicamente, pode haver tantas ortografias quanto há escritores” (p. 23).

"Que o jornal, a revista, o livro popular ou semi-popular, ou que, não sendo popular se destina todavia a um qualquer público presente, que não quer chocar - que essas publicações usem da ortografia preferida no seu país e no seu tempo ou momento, isso compreende-se, e seria absurdo que os autores ou publicadores desses impressos não procedessem assim, de mais a mais que os intuitos de tais publicações são predominantemente, ou fortemente, ou comerciais, ou publicitários ou propagandistas. Outro é o caso do autor que escreve na esperança de que sua obra fique (...)" (p. 27-28).

Não por acaso, o companheiro dos dois grandes escritores, anteriormente, flagrados em momentos de enfrentamentos metalingüísticos, de batalhas voltadas para questões lingüísticas, para a diversidade falada e escrita, é o brasileiro João Guimarães Rosa. Aqui não será pela voz de Riobaldo, de Miguelim ou de Diadorim que se vai surpreender uma linguagem roseanamente tecida, mas pela voz de um criador irado, narrador quase lingüista, quase filólogo a um triz do gramático, autor de um dos quatro prefácios que compõem a obra Tutaméia (Terceiras estórias). Trata-se de "Hipotrélico", um texto em que o escritor discute, pelo avesso, o direito à criação de palavras, à prática do neologismo, ao bisbilhotar os meandros da língua. Nesse caso especial, não sem muita ironia e muita malícia, o autor se coloca no papel de quem combate o "vezo de palavrizar" utilizando todos os argumentos que já foram usados contra ele e deixando à vista as inconsequiências e a falta de criatividade dos que se colocam diante da língua como puristas. 
Forjando o lembrete de que "um neologismo contunde, confunde, quase ofende", o autor simula a partir de uma suposta discussão em torno do termo hipotrélico, a postura de um empedernido filólogo defensor do status quo da língua: "sai todo mundo a empinar vocábulos seus, e aonde é que vai dar com a língua tida e herdada? Assenta-nos bem à modéstia achar que o novo não valerá o velho; ajusta-se à melhor prudência relegar o progresso no passado".

É, portanto, a partir das motivações sugeridas por esses três grandes escritores, que metalingüisticamente tocam no inevitável e plural imaginário existente em torno da língua enquanto patrimônio estável e enquanto possibilidades de usos, que se pode fazer a leitura da força que hoje alcançam na mídia alguns fenômenos de ensino do que se denomina norma culta, norma padrão, português correto, único e verdadeiro. Em franco contraste com a luta empreendida nas escolas, o sucesso do ensino do português na mídia se dá na medida em que o imaginário sobre a norma culta como realidade única da língua se instala no vídeo, na página do jornal, ali permanecendo como objeto da admiração e de um desejo deslocado e inatingível. Para finalizar pela mão de Clarice Lispector, poderíamos dizer que esse objeto do desejo poderia ser constituído de uma outra maneira, como se observa no trecho extraído do texto "Declaração de amor":

\footnotetext{
"Eu queria que a língua portuguesa chegasse ao máximo nas minhas mãos. E esse desejo todos os que escrevem têm. Um Camões e outros iguais não bastaram para nos dar para sempre uma herança de língua já feita. Todos nós que escrevemos estamos fazendo do túmulo do pensamento alguma coisa que lhe dê vida.

"Essas dificuldades nós as temos. Mas não falei do encantamento de lidar com uma língua que não foi aprofundada. O que recebi de herança não me chega" (p. 98-99).
}

Voltamos, portanto, também pelo caminho da literatura, a uma idéia mais rica e complexa de linguagem em que o sujeito, sem ser senhor e nem escravo da língua, como alguém já disse, e como os textos literários escolhidos procuram mostrar, insere-se na tradição e em seus movimentos e deslocamentos, enfrentando e sendo atravessado pelo imaginário, pois dele não pode escapar apenas fazendo de conta que não existe. Reconhecer a existência e as várias máscaras assumidas pelos curativos manuais de auto-ajuda, em que o indivíduo, o falante e o que escreve são tratados como doentes e a eles são ministrados remédios falsificados, talvez seja o primeiro passo para compreender o imaginário sobre a língua e suas formas de exploração como 
parte de ideologia que se revela sob outros signos, constituindo coerentemente a individualidade como bandeira.

\section{Bibliografia}

LISPECTOR, C. (1984/1994) Declaração de amor. In: A descoberta do mundo. 4. ed. Rio de Janeiro: Francisco Alves. p. 98-99.

FOLHA DE SÃO PAULO. Manual geral da redação (1987) 2. ed. São Paulo.

MARTINS, E. (org. e ed.) (1990) Manual de redação e estilo. São Paulo: O Estado de S. Paulo.

MOLIÈRE (1670/1965) Le bourgeois gentilhomme. Paris: Garnier-Flammarion. p. 69-142.

PESSOA, F. (1997) A língua portuguesa. Ed. Luísa Medeiros. Lisboa: Assírio \& Alvim.

POSSENTI, S. (1996) Por que (não) ensinar gramática na escola. Campinas: Mercado de Letras.

ROSA, J. G. (1967/1969) Hipotrélico. In: Tutaméia (Terceiras estórias). 4. ed. Rio de Janeiro: José Olympio. p. 64-69. 